\title{
Optimization of Stir Casting of Aluminum Matrix Composites (AMCs) with Filler of Recycled Glass Powder (RGP) for The Mechanical Properties
}

\author{
Yusup Hendronursito $^{1 *}$, Tumpal Ojahan ${ }^{2}$, Anang Anshori ${ }^{2}$, Asep Yunanto ${ }^{2}$ \\ ${ }^{1}$ Research Unit for Mineral Processing, Jl. Ir. Sutami Km. 15 Tanjung Bintang Lampung Selatan, \\ 35361, Indonesia \\ ${ }^{2}$ Department of Mechanical Engineering, Faculty of Engineering, University of Malahayati - \\ Lampung, Indonesia \\ *Corresponding author: yusuph_ugm07@yahoo.com
}

\begin{abstract}
A study of making Aluminum Matrix Composites (AMCs) uses recycled glass powder (RGP) as a filler has been carried out through the stir casting process. The experimental design uses the Taguchi method of $3^{\wedge} 3$ orthogonal array L9 with the parameters of powder size $(20>x>80,80>y>200,200>z>325)$, percentage of filler vs matrix $(2 \%, 7 \%, 12 \%)$, and stirring time (30 Seconds, 3 Minutes, 12 Minutes). The optimum conditions for the hardness of Al-GRp composites were obtained from specimens with Mesh powder size parameters 200> z>325, the percentage of glass vs aluminum powder was $12 \%$ wt, stirring time was 12 minutes. The experimental factor that has the greatest contribution to the hardness value of Al-GRP composites is the size of glass powder of $73.77 \%$, followed by the percentage of glass powder to aluminum by $19.98 \%$, and the stirring time of $1.21 \%$. The optimum experimental parameters for tensile strength can be obtained from specimens with particle size parameters of $20>x>80$, the percentage of glass powder to the weight of aluminum 12\%, and the stirring time of 30 seconds. The biggest contribution to the tensile strength value of the Al-GRP composite was the stirring time of $72.71 \%$, followed by the percentage of glass powder to aluminum by $13.67 \%$, and the size of the powder was $9.97 \%$.

Copyright @ 2020. Journal of Mechanical Engineering Science and Technology.

All rights reserved.
\end{abstract}

Keywords: Aluminum, composite, glass powder, mechanical, Taguchi method

\section{Introduction}

Aluminum matrix composites (AMCs) are a material that continues to be developed in the automotive and aircraft industries because it has several advantages such as high hardness, good strength to weight ratio, corrosion resistance, and so on [1]. The addition of filler in the form of $\mathrm{SiC}$ to AMCs has been shown to have an effect on superior mechanical properties. Silicon carbide or carborundum is a derivative of silicon compounds with the molecular formula $\mathrm{SiC}$. This material is formed by the covalent bonding of the elements $\mathrm{Si}$ with $\mathrm{C}$. The production process for $\mathrm{SiC}$ is complex and requires high energy which causes high costs. Synthesis of $\mathrm{SiC}$ at least requires a temperature of $1200^{\circ} \mathrm{C}$ at the furnace through microwave sintering furnace, plasma sintering, and hydrothermal processes to deform the $\mathrm{SiO}_{2}$ and $\mathrm{C}$ bonds into $\mathrm{SiC}$ [2] - [6]. Meanwhile, the synthesis of $\mathrm{SiC}$ using low temperatures is still a challenge for researchers [7]. Alternative materials are researched to obtain maximum results. The use of waste materials, such as glass waste, needs to be studied more deeply. 
Glass has a dominant content of $\mathrm{Si}$, so in this research, an experiment conducted on adding glass powder to aluminum composites. A reinforcing filler made from glass powder or what is often referred to as recycled glass powder (RGP) is one of the most widely used research materials as a reinforcement filler in composites [8]. The addition of RGP material as a filler in composites has been shown to reduce the expansion of the silica reaction so that the volume of the composite material is smaller [8]. The use of glass waste as a filler was also studied, stating that the use of glass waste can produce high strength and can reduce the porosity of composite materials [9]. The hardness of the oxide glass ranges from 5 to 7 on the Mohs scale, the highest obtained in silica glass. While the hardness of $\mathrm{SiO}_{2}$ and $\mathrm{CaO} . \mathrm{SiO}_{2}$ glass reaches $635 \mathrm{~kg} / \mathrm{mm}^{2}$ and $650 \mathrm{~kg} / \mathrm{mm}^{2}$ [10]. So it is possible to use it as a reinforcement that can be used to increase the hardness of aluminum matrix composites where the hardness of used aluminum waste based from piston is only $54 \mathrm{HRB}$ or equivalent to $98.4 \mathrm{~kg} / \mathrm{mm}^{2}$ [11]. Besides having the advantages that have been mentioned in several studies above, the use of waste as a composite material will provide an alternative to waste treatment, especially glass waste.

\section{Material and Methods}

The aluminum matrix used comes from automotive waste aluminum in the form of motor vehicle pistons. RGP as filler material is obtained from beverage glass bottles that have been refined on a ballmill machine and sieved to obtain the particles size. The casting method uses stirr casting, as shown in Figure 1.

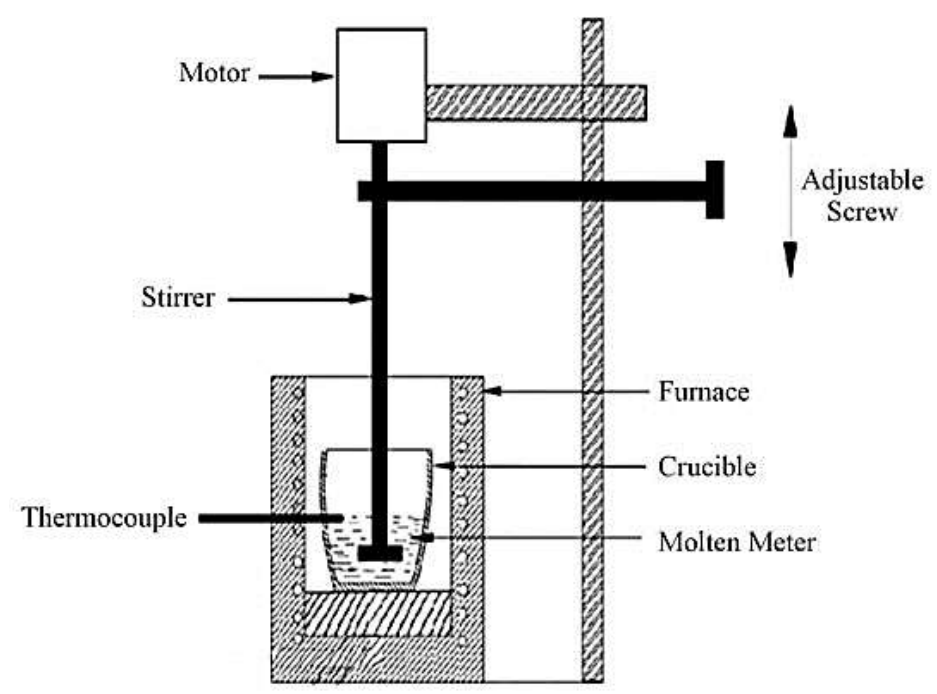

Fig. 1. Experimental schematic of stir casting machine [12]

The experimental design uses the Taguchi method of orthogonal array design L9 with 9 specimens. The parameters used in this study include powder size (mesh), percentage of glass powder to the weight of aluminum (\%), and stirring time (minutes). The parameter design using the Taguchi method can be seen in Table 1.

$\mathrm{S} / \mathrm{N}$ ratio large the better, optimizing by equation 1 .

$\frac{\mathrm{S}}{\mathrm{N}}=-10 \log \left[\frac{1}{\mathrm{n}} \sum_{\mathrm{i}=1}^{\mathrm{n}} \frac{1}{\mathrm{yi}^{2}}\right]$

Where $\mathrm{n}=$ number of observations and $\mathrm{y}=$ observed data 
The choice of level in variable powder size is based on the classification of size groups which are divided into 3 groups, namely large, medium, and small particle sizes. Group 1 has a particle size of $840 \mu \mathrm{m}$ to $177 \mu \mathrm{m}$, group 2 with a particle size of $177 \mu \mathrm{m}$ to $74 \mu \mathrm{m}$, and group 3 with a particle size of $74 \mu \mathrm{m}$ to $37 \mu \mathrm{m}$. Particle sizes greater than $1 \mu \mathrm{m}$ allow less perfect integration with the matrix due to the influence of heat on the stirr casting process.

Table 1. Taguchi: L9 orthogonal array

\begin{tabular}{clcl}
\hline No. sample & \multicolumn{1}{c}{ A } & B & \multicolumn{1}{c}{$\mathrm{C}$} \\
\hline Run order & Powder size & $\%$ Powder vs Al & Stirring time \\
\hline 1 & $20>\mathrm{x}>80$ & $2 \%$ & 30 Seconds \\
2 & $20>\mathrm{x}>80$ & $7 \%$ & 3 minutes \\
3 & $20>\mathrm{x}>80$ & $12 \%$ & 12 minutes \\
4 & $80>\mathrm{y}>200$ & $2 \%$ & 3 minutes \\
5 & $80>\mathrm{y}>200$ & $7 \%$ & 12 minutes \\
6 & $80>\mathrm{y}>200$ & $12 \%$ & 30 Seconds \\
7 & $200>\mathrm{z}>325$ & $2 \%$ & 12 minutes \\
8 & $200>\mathrm{z}>325$ & $7 \%$ & 30 Seconds \\
9 & $200>\mathrm{z}>325$ & $12 \%$ & 3 minutes \\
\hline
\end{tabular}

Sample testing to determine the optimization of the process that has been designed includes mechanical tests in the form of hardness and tensile strength. The hardness test uses the Rockwell hardness tester while the tensile strength test uses the Universal Testing Machine (UTM) HT 2402 with a capacity of $100 \mathrm{kN}$ at the Non Metal Material Laboratory, BPTM - LIPI by following the ASTM E8-M standard.

\section{Results and Discussions}

\section{A. Taguchi Analysis for Composite Hardness}

Hardness testing is carried out on the sample at several points and take the average value for Taguchi and Anova analysis. The hardness value obtained from an average of three times the test, as shown in Table 2.

The results of the Taguchi analysis include the S/N ratio and means value are shown in Table 3 and Figures 2 - 3. The ranking of each experimental factor is shown in Table 3 where powder size gets the first rank, percentage of GRP powder to basalt 2nd rank, and stirring time 3rd rank. This rating shows the most dominant value on the test results, in this case the hardness of the composite.

Main effects plots for means show the average value of each parameter and the levels that can be achieved. The highest average value for factor A is obtained from level 3, factor B is obtained from level 3, and factor $\mathrm{C}$ is obtained at level 3. From the main effects plot graph for the average value in Figure 2, it can be seen that factor A indicates the existence of increase in the average score at each level. 
Table 2. Results of hardness testing

\begin{tabular}{ccccc}
\hline \multirow{2}{*}{$\begin{array}{c}\text { No } \\
\text { sample }\end{array}$} & \multicolumn{3}{c}{ Experimental parameters } & $\begin{array}{c}\text { Hardness test } \\
\text { results (average) } \\
\text { nynn }\end{array}$ \\
\cline { 2 - 4 } & A (Powder size) & B (\% Powder vs Al) & C (Stirring time) & HRB \\
\hline 1 & 1 & 1 & 1 & 58 \\
2 & 1 & 2 & 2 & 60 \\
3 & 1 & 3 & 3 & 72 \\
4 & 2 & 1 & 2 & 78 \\
5 & 2 & 2 & 3 & 81 \\
6 & 2 & 3 & 1 & 88 \\
7 & 3 & 1 & 3 & 83 \\
8 & 3 & 2 & 1 & 87 \\
9 & 3 & 3 & 2 & 92 \\
\hline
\end{tabular}

Table 3. Response larger is better of $\mathrm{S} / \mathrm{N}$ ratios for hardness value

\begin{tabular}{lcccc}
\hline \multirow{2}{*}{ Experiment factors } & \multicolumn{4}{c}{ Response for levels in factor parameters } \\
\cline { 2 - 5 } & 1 & 2 & 3 & Ranking \\
\hline A (Powder size) & 35.99 & 38.30 & 38.82 & 1 \\
B (\% Powder vs Al) & 37.16 & 37.51 & 38.44 & 2 \\
C (Stirring time) & 37.65 & 37.56 & 37.90 & 3 \\
\hline
\end{tabular}

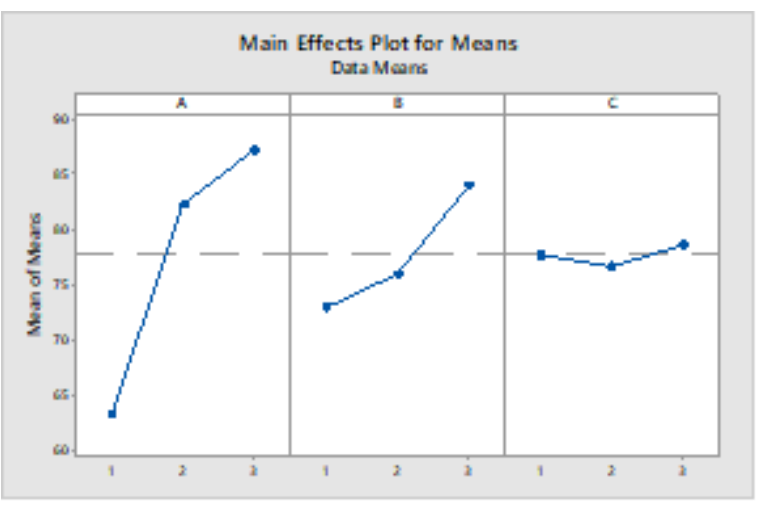

Fig. 2. Main effects plot for Means to the hardness value

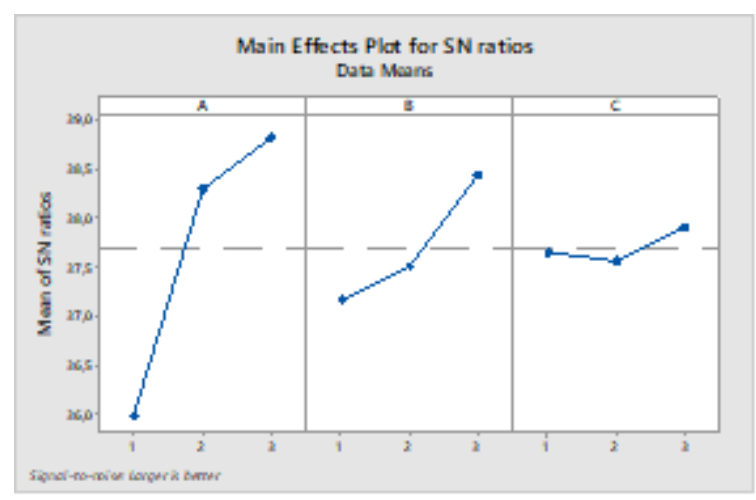

Fig. 3. Main effects plot for $\mathrm{S} / \mathrm{N}$ (Larger is better) ratio to the hardness value

The effect of the size of the glass powder as a filler shows an increase from the size of $20>x>80$ of $63.33 \mathrm{HRB}$ to $82.33 \mathrm{HRB}$ at the powder size of $80>\mathrm{y}>200$ and it increases again when the powder size is $200>\mathrm{z}>325$ to $87.33 \mathrm{HRB}$. The change in powder size from large to smaller sizes has a directly proportional effect on the average value of hardness. The smaller of the size, the greater the average hardness obtained. Likewise in factor B, it can be seen that the average value is directly proportional to the level used. At level 1 the percentage of glass powder to aluminum is $2 \% \mathrm{w} / \mathrm{t}$, has an average hardness value of 73 $\mathrm{HRB}$,increases to $76 \mathrm{HRB}$ at level 2 with the percentage of glass powder to aluminum is $7 \% \mathrm{w} / \mathrm{t}$, and again increases to $84 \mathrm{HRB}$ at level 3 with the percentage of glass powder to 
aluminum is $12 \%$ w/t. However, it is different in factor $\mathrm{C}$; there is a value that goes up and down at level 1 and falls at level 2 and rises to reach a peak at level 3. Level 1 of $\mathrm{C}$ parameter, namely the stirring time of 30 seconds, gives an average hardness value of 77.67 HRB and decreased to 76.67 HRB when stirring for 3 minutes.

From the $\mathrm{S} / \mathrm{N}$ ratios graph in Figure 3, it can be seen that the optimum conditions are at the following parameters and levels: $\mathrm{A} 3 \mathrm{~B} 3 \mathrm{C} 3$. The optimum conditions for $\mathrm{A} 3 \mathrm{~B} 3 \mathrm{C} 3$ represent the sample with the following parameters, A3 is the size of the mesh powder $200>\mathrm{z}>325, \mathrm{~B} 3$ is The percentage of glass powder vs aluminum is $12 \% \mathrm{w} / \mathrm{t}$, and C3 is the stirring time of 12 minutes.

\section{B. Analysis of Variance (Anova) for Composite Hardness}

Anova using the Minitab 17 software can be used to determine the significant parameters that affect the hardness results. The variables used in this experiment include $\mathrm{A}$ (RGP size in mesh), B (percentage of glass powder vs Aluminum), C (stirring time). This significant effect can be seen from the P-value obtained from the results of data processing. Important requirements in drawing conclusions based on data or statistical groups are as follows:

If the P-Value $>\alpha$, then hypothesis zero (Ho) is accepted, and hypothesis one (H1) is rejected. If the P-Value $<\alpha$, then hypothesis Zero $(\mathrm{Ho})$ is rejected and hypothesis one $(\mathrm{H} 1)$ is accepted. The $\alpha$ value in the experiment was set at $5 \%$.

The null hypothesis of the Anova test states that there is no relationship between the independent variable and the dependent variable. This means that in the formulation of the hypothesis being tested is the conclusion that it is not true that the independent variable affects the dependent variable. The alternative hypothesis (H1) states that there is a relationship between the independent variable $(\mathrm{x})$ and the dependent variable $(\mathrm{y})$ under study. This means that in the formulation of the hypothesis, the conclusion is that the results of the $\mathrm{H} 1$ calculation will be used as the basis for searching research data.

The Anova test results are shown in Table 4. From these results, the P-value is obtained from the smallest value to the largest value, respectively, are parameter A with a value of 0.000 , parameter $B$ with a value of 0.001 , and parameter $C$ with a value of 0.323 . This concludes that for parameter A and parameter B then Ho is rejected and H1 is accepted. The size of the powder and the percentage of glass powder on aluminum have a significant effect on the hardness of the composite. While the parameter $\mathrm{C}$ value of $\mathrm{P}$-value is greater when compared to $\alpha=5 \%$. So that in this study, the stirring time did not have a significant effect on the hardness of aluminum composites. The analysis of Anova, the Pvalue in accordance with the Taguchi test in Table 3, which shows the highest ranking is obtained from parameter A (grain size of glass powder).

Based on Figure 4, the experimental factor that has the largest contribution to the hardness value of Al-GRP composites is the size of glass powder of $73.77 \%$, followed by the percentage of glass powder to aluminum by $19.98 \%$, an error of $5.04 \%$, and stirring time of $1,21 \%$. Based on the Taguchi test of the $\mathrm{S} / \mathrm{N}$ ratios value, the optimum grain size to use was $200>\mathrm{z}>325$ mesh. A filler with good characteristics will have positive effect on the composites made. The RGP filler has a high hardness that will increase the hardness distribution of the aluminum matrix composite. The presence of harder filler and well bonded RGP particles in aluminum matrix that impede the movement of dislocations increases the hardness of AMCs [13]. 
Table 4. Anova test results on the hardness (HRB) of Al-GRP

\begin{tabular}{lcccccc}
\hline \multicolumn{1}{c}{ Source } & DF & Seq SS & Adj SS & Adj MS & F-Value & P-value \\
\hline Regression & 3 & 1049.97 & 1049.97 & 349.99 & 31.39 & 0.001 \\
A (Powder size) & 1 & 815.66 & 815.66 & 815.66 & 73.15 & 0.000 \\
B (\% Powder vs Al) & 1 & 220.9 & 220.9 & 220.9 & 19.81 & 0.007 \\
C (Stirring time) & 1 & 13.41 & 13.41 & 13.41 & 1.2 & 0.323 \\
Error & 5 & 55.76 & 55.76 & 11.15 & & \\
Total & 8 & 1105.73 & & & & \\
\hline
\end{tabular}

The contribution of each factor to the hardness value of the Al-GRP composites is shown in Figure 4.

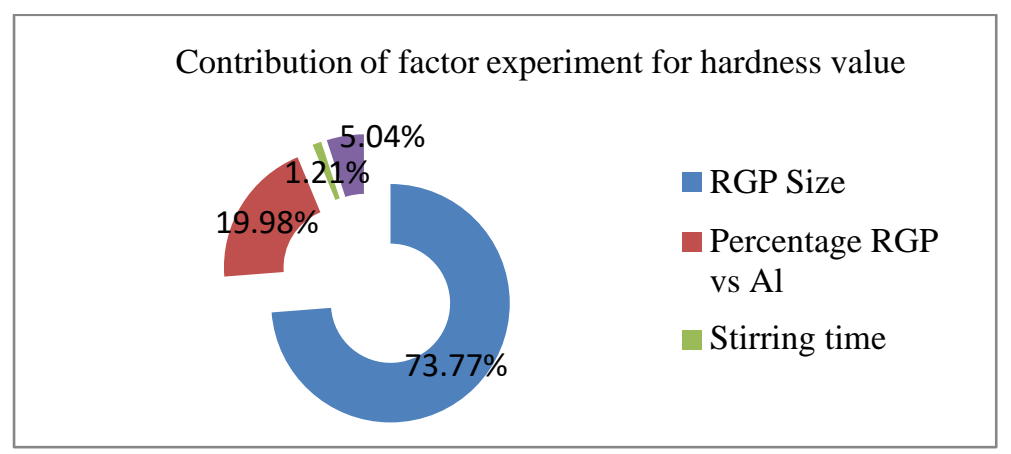

Fig. 4. Contribution of experimental factors to the hardness of Al-GRP composites

Based on Table 5, it is known that the coefficient of determination R-Square is 0.9496, which is the square of the correlation coefficient " $\mathrm{R}$ " which is 0.9745 . The coefficient of determination of 0.9496 indicates the independent variable (x) simultaneously (together) affects the dependent variable (y) by $94.96 \%$. While the remaining $5.04 \%$ is influenced by other variables outside the regression equation or other variables that are not included in the experimental parameters. The magnitude of the influence of this other variable is called error. The value of R-sq, which is close to the value of $100 \%$, indicates that the influence of the independent variable $(\mathrm{x})$ is getting stronger on the dependent variable $(\mathrm{y})$.

Table 5. Output model summary

\begin{tabular}{cllll}
\hline \multicolumn{4}{c}{ Model summary for transformed response } \\
\hline S & R-sq & R-sq (adj) & Press & R-sq (pred) \\
\hline 3.33935 & $94.96 \%$ & $91.93 \%$ & 156.242 & $85.87 \%$ \\
\hline
\end{tabular}

The formula for predicting the hardness value of Al-GRP composites in terms of the factors and levels used in this experiment are as follows:

$$
\begin{aligned}
& \mathrm{HRB}=77.667-14.333 \mathrm{~A} \_1+4.667 \mathrm{~A} \_2+9.667 \mathrm{~A} \_3-4.667 \mathrm{~B} \_1 \text { - } 1.667 \mathrm{~B} \_2 \\
& +6.333 \text { B_3 }+0.0 \text { C_1 }-1.000 \text { C_2 }+1.000 \text { C_3 }
\end{aligned}
$$


From equation (2), it can be seen that the value of hardness without independent variables $(\mathrm{A}, \mathrm{B}, \mathrm{C})$ is predicted to be at a value of $77 \mathrm{HRB}$. Important factors that affect the value of hardness which is indicated by the high regression coefficient values, namely A1 and A3. This is in accordance with the ranking obtained from Table 3. It is also seen that the factor that is not too influential is the length of stirring (C) with a small regression coefficient value. In addition to predicting the hardness value obtained by multiplying the number against the experimental factor, it can also be predicted the value of hardness through the relationship of two parameters used, for example, the interaction between parameter $\mathrm{A}$ and parameter $\mathrm{B}$ (A vs B), parameter A with parameter C (A vs C), and parameter $b$ with parameter $C$ (A vs $C$ ).

Based on Figure 5, the contour plot of the hardness value of the interaction of parameter A and parameter B, it can be seen that the highest hardness value is symbolized in the dark green area. This area is obtained when the level on parameter A and parameter $\mathrm{B}$ increases.

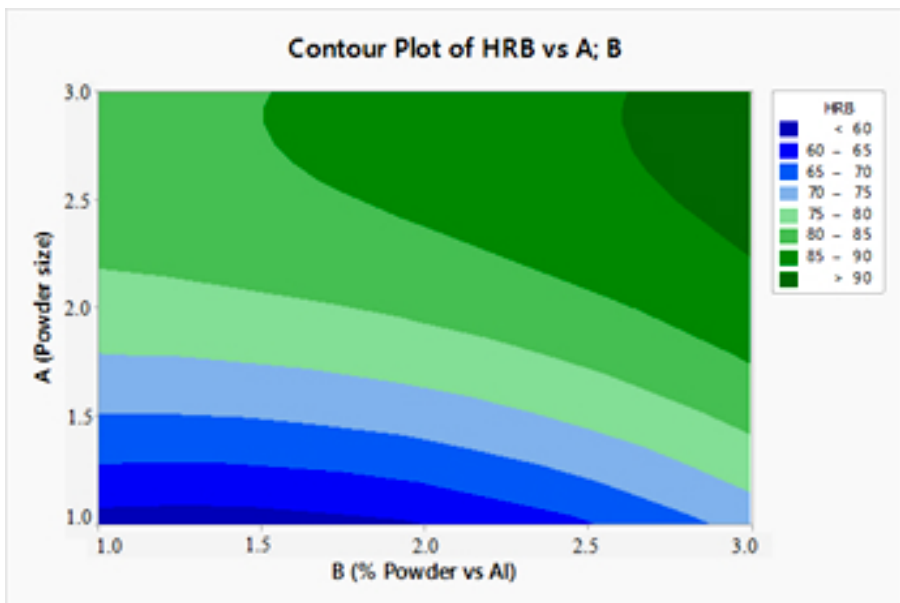

Fig. 5. Prediction of the relationship between A vs B and the resulting violence

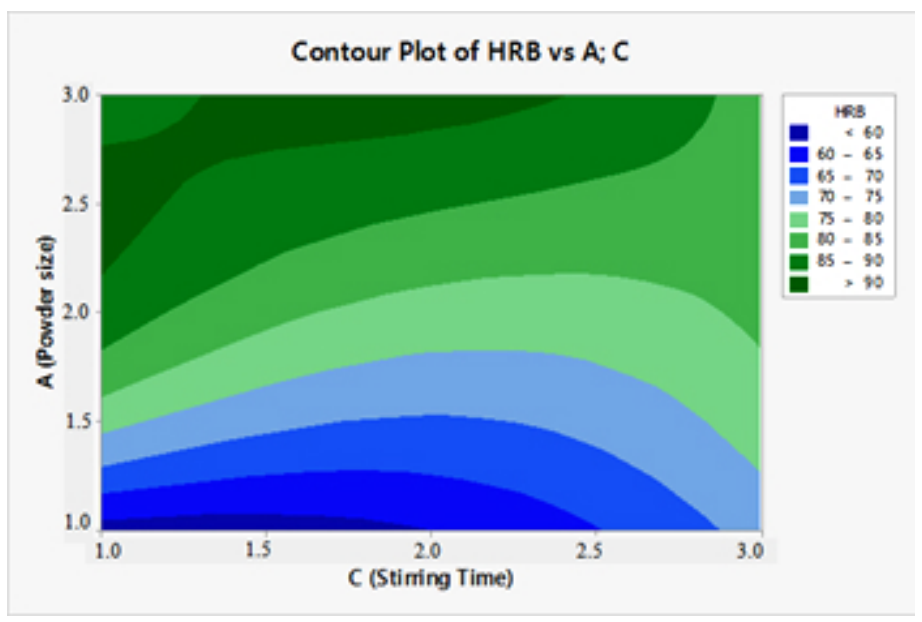

Fig. 6. Prediction of A vs C relationship to the resulting violence

In the contour plot of hardness obtained from the interaction of parameter $\mathrm{A}$ and parameter $\mathrm{C}$ as shown in Figure 6, it can be seen that the highest hardness value can be 
obtained in parameter A starting at level 2 to 3, but parameter $\mathrm{C}$ is the choice of level that can be used from level 1 to level 2.5.

The prediction of the relationship between $\mathrm{B}$ vs $\mathrm{C}$ and the resulting hardness can be seen in Figure 7. The area bordered by dark green is the area with the highest hardness value, more than $90 \mathrm{HRB}$. When seen in the picture, this area is very narrow. This is in accordance with the significant contribution and influence that these two parameters contribute less and less significant effect on violence.

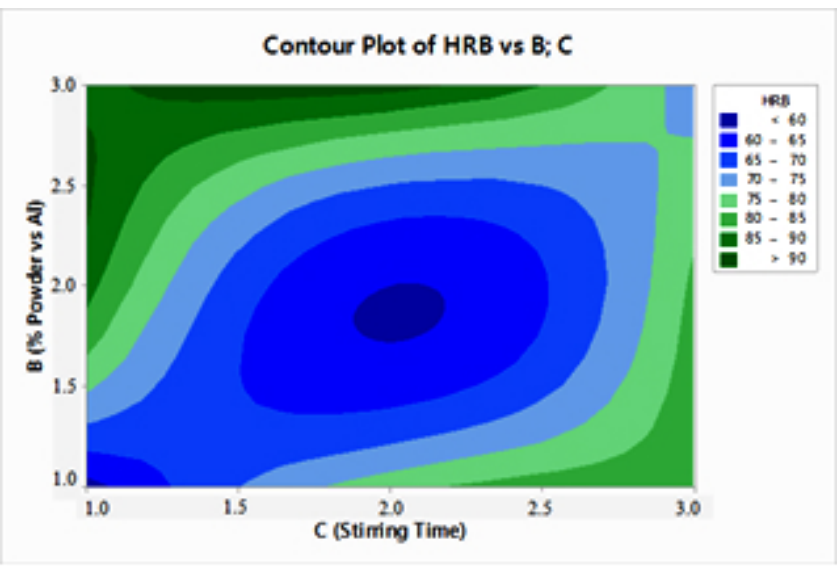

Fig. 7. Prediction of the relationship between $\mathrm{B}$ vs $\mathrm{C}$ and the resulting violence

\section{Taguchi Analysis for Composite Tensile Strength}

The results of the test for the tensile strength of the Al-GRP composite sample are shown in Table 6. The highest tensile strength was obtained from sample 6th is 11.24 $\mathrm{N} / \mathrm{mm}^{2}$. Sample 6th was obtained from various parameters and levels of A2B3C1, with parameters of glass powder grain size $80>y>200$, percentage of glass powder vs aluminum $12 \% \mathrm{w} / \mathrm{t}$, stirring time 30 seconds. While the lowest value is obtained from sample 4th with a tensile strength value of $2.76 \mathrm{~N} / \mathrm{mm}^{2}$. Sample 4th was obtained from A2B1C2 parameters, namely glass powder grain size $80>y>200$, percentage of glass powder vs aluminum $2 \% \mathrm{w} / \mathrm{t}$, stirring time 3 minutes.

Table 6. Tensile strength results

\begin{tabular}{|c|c|c|c|c|}
\hline \multirow{2}{*}{$\begin{array}{l}\text { No } \\
\text { sample }\end{array}$} & \multicolumn{3}{|c|}{ Experimental parameters } & \multirow{2}{*}{$\begin{array}{l}\text { Tensile strength } \\
\quad(\mathrm{N} / \mathrm{mm} 2)\end{array}$} \\
\hline & $\begin{array}{l}\text { A (Powder } \\
\text { size) }\end{array}$ & $\begin{array}{c}\text { B } \\
\text { (\% Powder vs Al) }\end{array}$ & $\begin{array}{c}\mathrm{C} \text { (Stirring } \\
\text { time) }\end{array}$ & \\
\hline 1 & 1 & 1 & 1 & 9.55 \\
\hline 2 & 1 & 2 & 2 & 4.66 \\
\hline 3 & 1 & 3 & 3 & 8.14 \\
\hline 4 & 2 & 1 & 2 & 2.76 \\
\hline 5 & 2 & 2 & 3 & 2.81 \\
\hline 6 & 2 & 3 & 1 & 11.24 \\
\hline 7 & 3 & 1 & 3 & 4.15 \\
\hline 8 & 3 & 2 & 1 & 8.15 \\
\hline 9 & 3 & 3 & 2 & 3.66 \\
\hline
\end{tabular}


The response data from the tensile test results are then processed to create a response table for the average tensile strength and the $\mathrm{S} / \mathrm{N}$ ratios table. The results of data processing are shown in Table 7 and Figure 8 - 9.

Table 7 shows the ranking of factor parameter. It has shown the stirring time give the best ranking followed by percentage of glass powder and powder size, respectively.

Table 7. Response of $\mathrm{S} / \mathrm{N}$ ratios larger is better $(\mathrm{dB})$ for tensile strength

\begin{tabular}{lcccc}
\hline \multirow{2}{*}{ Experiment factors } & \multicolumn{5}{c}{ Response for levels in factor parameters } \\
\cline { 2 - 5 } & 1 & 2 & 3 & Ranking \\
\hline A (Powder size) & 17.06 & 12.94 & 13.95 & 3 \\
B (\% Powder vs Al) & 13.59 & 13.52 & 16.83 & 2 \\
C (Stirring Time) & 19.61 & 11.15 & 13.18 & 1 \\
\hline
\end{tabular}

The effect of reducing the grain size of glass powder from mesh $20>x>80$ to 200> z> 325 causes the average tensile strength of the composites to decrease by $28.59 \%$. The tensile strength of the composite decreased from 7.45 to $5.32 \mathrm{~N} / \mathrm{mm}^{2}$. Meanwhile, by increasing the percentage of glass powder from $2 \% \mathrm{w} / \mathrm{t}$ to $12 \%$ by weight of aluminum, it can increase the tensile strength from $13.59 \mathrm{~N} / \mathrm{mm}^{2}$ to $16.83 \mathrm{~N} / \mathrm{mm}^{2}$. However, the percentage of $7 \%$ wt of glass powder to aluminum decreased slightly by around 0.07 $\mathrm{N} / \mathrm{mm}^{2}$. However, this value tends to be small, namely around $0.5 \%$, the graphical trend that is increasing with the addition of the percentage of glass powder. In the parameter of stirring time, there was a decrease in the tensile strength value of the Al-GRC composite by $47.83 \%$. Stirring time of 30 seconds gives the highest average tensile strength value of $9.647 \mathrm{~N} / \mathrm{mm}^{2}$, presented in Figure 9.

$\mathrm{S} / \mathrm{N}$ ratio analysis shows the effect of the most optimum experimental parameters that can be obtained from the experimental parameters, namely A1B3C1. A1B3C1 parameter represents particle size $20>\mathrm{x}>80$, percentage of glass powder to weight of aluminum $12 \%$, and stirring time 30 seconds.

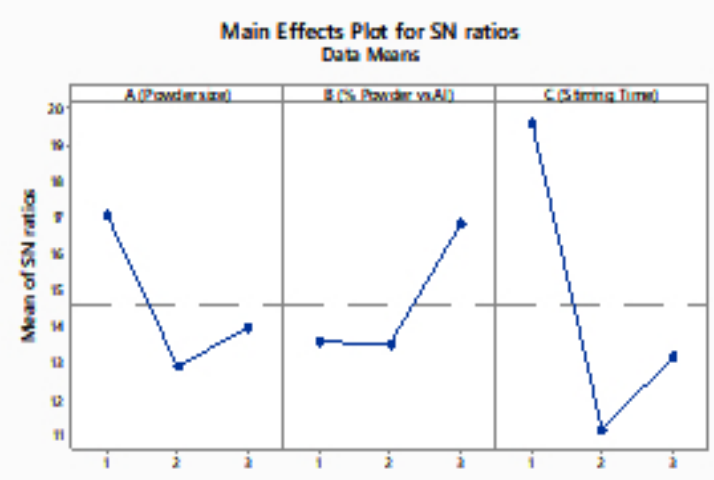

Fig. 8. Effect of experimental factors on $\mathrm{S} / \mathrm{N}$ Ratios larger is better for tensile strength

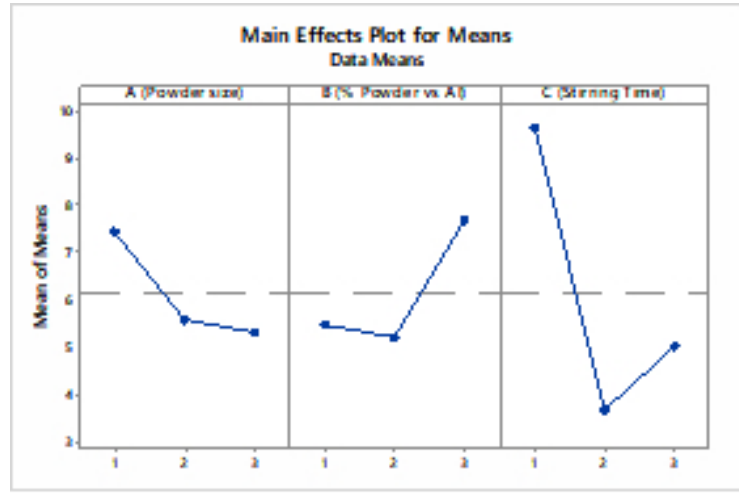

Fig. 9. The main effects of experimental factors on the average tensile strength of the Al-GRP composite 


\section{Analysis of Variance (Anova) for Composite Tensile Strength}

The Anova test results are shown in Table 8. From these results, the P-value from the smallest to the largest value is parameter $C$ with a value of 0.048 , parameter $B$ with a value of 0.211 and parameter A with a value of 0.268 , respectively. This concludes that in parameter $\mathrm{C}$, Ho is rejected and $\mathrm{H} 1$ is accepted. The duration of stirring has a significant effect on the tensile strength of the composite. While parameter A and parameter B, the Pvalue is greater when compared to $\alpha 5 \%$. So that in this study, the grain size of glass powder and the percentage of glass powder on the weight of aluminum did not have a significant effect on the tensile strength of aluminum composites. The analysis of ANOVA shows conformity to the ranking results obtained from Table 7. Anova analysis, the Pvalue for the conclusion of the hypothesis taken is in accordance with the Taguchi test, which shows that the highest ranking is obtained from parameter $\mathrm{C}$ (stirring time).

Table 8. Anova test results on tensile strength $\left(\mathrm{N} / \mathrm{mm}^{2}\right)$ of Al-GRP composites

\begin{tabular}{ccccccc}
\hline Source & DF & Seq SS & Adj SS & Adj MS & F-Value & P-value \\
\hline A (Powder size) & 2 & 8.027 & $8 ., 027$ & 4.014 & 2.73 & 0.268 \\
B (\% Powder vs Al) & 2 & 11.006 & 11.006 & 5.503 & 3.75 & 0.211 \\
C (Stirring time) & 2 & 58.521 & 58.521 & 29.26 & 19.93 & 0.048 \\
Error & 2 & 2.936 & 2.936 & 1.468 & & \\
Total & 8 & 80.49 & & & & \\
\hline
\end{tabular}

The contribution of each factor to the tensile strength value of the Al-GRP composite is shown in Figure 10.

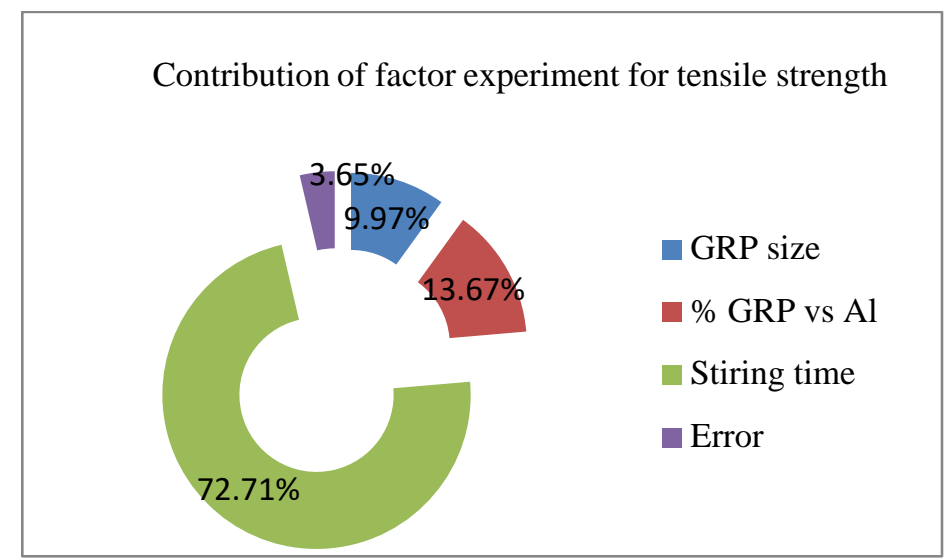

Fig. 10. Contribution of experimental factors to the tensile strength of Al-GRP composites

Based on Figure 10, the experimental factor that has the greatest contribution to the tensile strength value of Al-GRP composites is the stirring time of $72.71 \%$, followed by the percentage of glass powder to aluminum by $13.67 \%$, powder size of $9.97 \%$, and $3.65 \%$. Based on the Taguchi test of the $\mathrm{S} / \mathrm{N}$ ratios value, the optimum stirring time is 30 seconds. The stirrer rotation makes a vortex effect that draws the particle into the aluminum melt. The filler needs to be subjected to constant centrifugal currents over a certain period of 
time to achieve dispersion all through the aluminum melt. Longer stirring time produces more agitation in the molten composite, which increases the tendency to form more porosity. There is an optimum range of stirring time to achieve uniform distribution with least porosity. If stirring continues beyond the optimum range, the gas absorbability of the molten aluminum will increase. Thus, the formation of porosity becomes unavoidable [14].

Based on Table 9. Output model summary, it is known that the coefficient of determination R-Square is 0.9435 which is the square of the correlation coefficient "R", which is 0.9816 . The coefficient of determination of 0.9435 indicates that the independent variable (x) simultaneously (together) affects the dependent variable (y) by $94.35 \%$. While the rest, $5.65 \%$ is influenced by other variables outside the regression equation or other variables that are not included in the experimental parameters. The magnitude of the influence of this other variable is called error. The value of R-sq, which is close to the value of $100 \%$, indicates that the influence of the independent variable (x) is getting stronger on the dependent variable $(\mathrm{y})$.

Table 9. Output model summary

\begin{tabular}{ccccc}
\hline \multicolumn{5}{c}{ Model summary for transformed response } \\
\hline S & R-sq & $\begin{array}{c}\text { R-sq } \\
\text { (adj) }\end{array}$ & Press & $\begin{array}{c}\text { R-sq } \\
\text { (pred) }\end{array}$ \\
1.21156 & $96.35 \%$ & $85.41 \%$ & 59.449 & $26.14 \%$ \\
\hline
\end{tabular}

The formula for predicting the tensile strength of the Al-GRP composite in terms of the factors and levels used in this experiment are as follows:

Tensile Strength $=6.124+1.326 \mathrm{~A} \_1-0.521 \mathrm{~A} \_2-0.804 \mathrm{~A} \_3-0.638 \mathrm{~B} \_1-0.918 \mathrm{~B} \_2$ $+1.556 \mathrm{~B} \_3+3.522 \mathrm{C} \_1-2.431 \mathrm{C} \_2-1.091 \mathrm{C} \_3$

From equation (3), it can be seen that the value of tensile strength without independent variables $(A, B, C)$ is predicted to be at a value of $6.124 \mathrm{~N} / \mathrm{mm}^{2}$. Important factors that affect the value of tensile strength which is indicated by the high regression coefficient values, namely $\mathrm{C} 1$ and $\mathrm{C} 2$. This is in accordance with the ranking obtained from Table 3 . It is also seen that the factor that is not too influential is the particle size (A) and percentage of GRP (B) with a small regression coefficient value. In addition to predicting the tensile strength obtained by multiplying the number against the experimental factor, it can also be predicted the value of tensile strength through the relationship of the two parameters used, for example, the interaction between parameter A and parameter B (A vs B), parameter A with parameter $\mathrm{C}$ (A vs $\mathrm{C}$ ), and parameter $\mathrm{B}$ with parameter $\mathrm{C}$ (A vs $\mathrm{C}$ ).

Based on Figure 11, the contour plot of the tensile strength from the interaction of parameter A and parameter B, it can be seen that the tensile strength is symbolized in the dark green area with a tensile strength value greater than $3 \mathrm{~N} / \mathrm{mm}^{2}$ obtained from parameter A level 2 and parameter B level 2. The area with a high tensile strength value is very narrow and the tensile strength value obtained is also very small (above $3 \mathrm{~N} / \mathrm{mm}^{2}$ ). It can be understood from the previous explanation that these two parameters (parameter $\mathrm{A}$ and parameter B) do not contribute simultaneously to the tensile strength value of the AlGRP composite. 


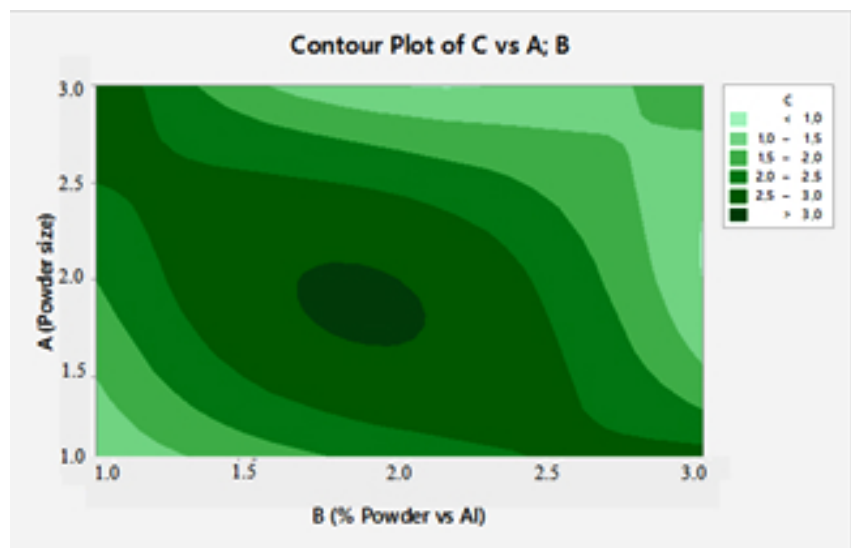

Fig. 11. Contour plot of parameter A vs parameter B to tensile strength

In the contour of tensile strength plot in Figure 12, which is obtained from the interaction of parameter $\mathrm{A}$ and $\mathrm{C}$, it can be predicted that the highest tensile strength value is obtained from parameter $\mathrm{A}$ at any level as long as it interacts with parameter C level 2.5 to level 3. This is in accordance with the explanation contribution of parameter $\mathrm{C}$, which holds the highest and most significant contribution to tensile strength.

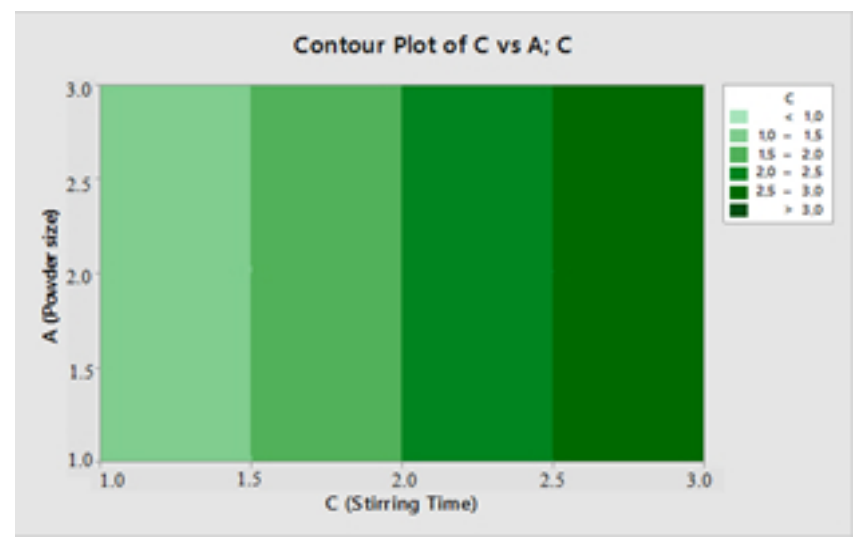

Fig. 12. Prediction of $\mathrm{A}$ vs $\mathrm{C}$ relationship to the resulting violence

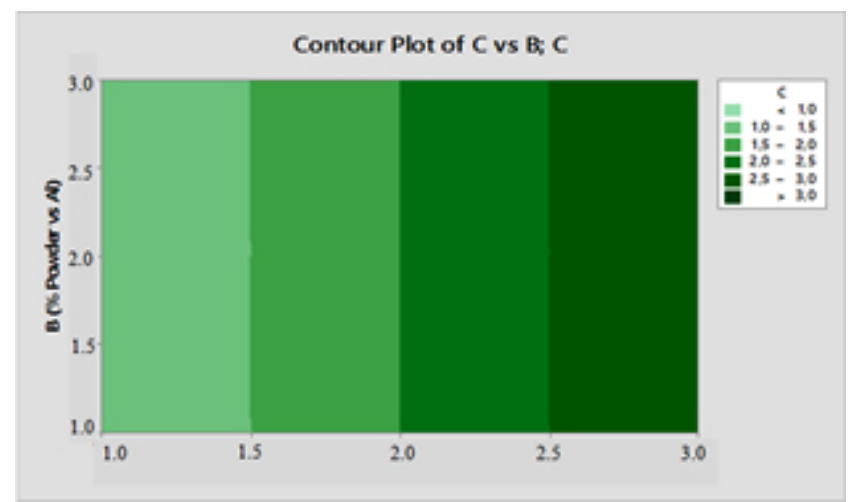

Fig. 13. Prediction of the relationship between $B$ vs $C$ and the resulting violence

The prediction of the relationship between $\mathrm{B}$ vs $\mathrm{C}$ and the resulting tensile strength can be seen in Figure 13. The area bordered by dark green is the area with the highest tensile 
strength, more than $3 \mathrm{~N} / \mathrm{mm}^{2}$. It can be predicted that the highest tensile strength value is obtained from any level of parameter B as long as it interacts with parameter C level 2.5 to level 3. This is in accordance with the explanation of the contribution of parameter $\mathrm{C}$, which holds the highest contribution and has the most significant effect on tensile strength.

\section{Conclusions}

The manufacture of aluminum matrix composites (AMCs) made from aluminum matrix with glass powder reinforcing filler has been carried out by the stirr casting process using a variety of experimental factors designed using Taguchi and analyzed using the help of Minitab 17 software.

The optimum conditions for the hardness of Al-GRp composites were obtained from specimens with particle size parameters 200> z $>325$, the percentage of glass vs aluminum powder was $12 \% \mathrm{w} / \mathrm{t}$, stirring time was 12 minutes. The experimental factor that has the greatest contribution to the hardness value of Al-GRP composites is the size of glass powder of $73.77 \%$, followed by the percentage of glass powder to aluminum by $19.98 \%$, and the stirring time of $1.21 \%$. The optimum experimental parameters for tensile strength can be obtained from specimens with particle size parameters of $20>x>80$, the percentage of glass powder to the weight of aluminum 12\%, and the stirring time of 30 seconds. The biggest contribution to the hardness value of the Al-GRP composite was the stirring time of $72.71 \%$, followed by the percentage of glass powder to aluminum by $13.67 \%$, and the size of the powder was $9.97 \%$.

\section{Acknowledgement}

The first author is the main contributor, while the other authors are the member contributors to this paper. The authors full thank to Mr. Gusri Akhyar Ibrahim who give knowledge about design experiment, especially in Taguchi and analysis of variance. Tensile and hardness testing is carried out using testing services in the Indonesian Institute of Sciences - LIPI Laboratory.

\section{References}

[1] Sahin, Y., and Murphy, S., "The effect of fiber orientation of the dry sliding wear of borsic reinforced aluminum alloy", Journal of materials science, vol. 31, pp. 5399 5407, October 1996.

[2] Krishnarao, R.V., \& Subrahmanyam, J., "Formation of SiC from rice husk black mixture: effect of rapid heating", Ceramics international, vol. 22 (6), pp. 489 492, February 1999.

[3] Pei, L.Z., Tang, Y.H., Chen, Y.W., Guo, C., Li, X.X., Yuan, Y., and Zhang, Y., "Preparation of silicon carbide nanotubes by hydrothermal method", Journal of applied physics, vol. 99, pp. 114306, February 2006.

[4] Suparman, S., "Sintesis silikon karbida (SiC) dari silika sekam padi dan karbon kayu dengan metode reaksi fasa padat", Flux jurnal ilmiah fisika FMIPA Universitas Lambung Mangkurat, vol. 1(1), pp. 47, January 2019.

[5] Li, J., Shirai, T., and Fuji, M., "Rapid carbothermal synthesis of nanostructured silicon carbide particles and whiskers from rice husk by microwave heating 
method", Advanced powder technology, vol. 24 (5), pp. 838 - 834, September 2013.

[6] Laar, J.H., Van., Slabber, J.F.M., Meyer, J.P., Walt, I.J., Puts, G.J., and Crouse, P.L., "Microwave-plasma synthesis of nano-sized silicon carbide at atmospheric pressure", Ceramics international, vol. 41 (3), pp. 1-24. April 2015.

[7] Su, J., Gao, B., Chen, Z., Fu, J., An, W., Peng, X., Zhang, X., Wang, L., Huo, K., and Chu, P.K., "Large-scale synthesis and mechanism of $\beta$-SiC nanoparticles from rice husks by low-temperature magnesiothermic reduction", ACS sustainable chemistry and engineering, vol. 4 (12), pp. 6600-6607, October 2016.

[8] Parghi, A., and Alam, M.S., "Physical and mechanical properties of cementitious composites containing recycled glass powder (RGP) and styrene butadin rubber (SBR)", Construction and buliding materials, vol. 104, pp. 34-43, Febuary 2016.

[9] Lee, H., Hanif, A., Usman, M., Sim, J., and Oh, H., "Performance evaluation of concrete incorporating glass powder and glass sludge wastes as supplementary cementing material", Journal of Cleaner Production, vol. 170, pp. 683-693, January 2018.

[10] Yamane, M., and Mackenzie, J.D., "Vicker's hardness of glass", Journal of noncrystalline solids, vol. 15 (2), pp. 153-164, June 1974.

[11] Hendronursito, Y., Rajagukguk, T.O., Safii, R.N., Sofii, A., Isnugroho, K., Birawidha, D.C., Muttaqii, M.Al., "Analysis of aluminium basalt particulate composite using stirring casting method through taguchi method approach", in Materials science and engineering, IOP conference series, 1-6.

[12] Haque, S., Ansari, A.H., and Bharti, P.K., "Effect of process parameters on wear rate of al 6061-cu reinforced sic p metal matrix composites", Journal of materials and environmental science, vol. 5 (5), pp. 1485-1489, January 2014.

[13] Rahman, M.H., and Al Rashed, H.M., "Characterization of silicon carbide reinforced aluminum matrix composites", in 10th International Conference on Mechanical Engineering, ICME 2013, Procedia engineering, 103-109.

[14] Moses, J.J., Dinaharan, I., Sekhar, S.J., "Predicting the influence of process parameters on tensile strength of AA6061/TiC aluminum matrix composites produced using stir casting", Transactions of nonferrous metals society of China, vol. 26 (6), pp. 1498-1511, June 2006. 